\title{
Erratum to: Treatment of camptocormia with continuous subcutaneous infusions of apomorphine: 1-year prospective pilot study
}

\author{
Katerina Mensikova • Michaela Kaiserova • \\ Miroslav Vastik • Sandra Kurcova • \\ Petr Kanovsky
}

Published online: 21 March 2015

(C) Springer-Verlag Wien 2015

\section{Erratum to: J Neural Transm \\ DOI 10.1007/s00702-014-1297-9}

In the original publication of this article, the author names were transposed: the first names were presented as last names and the last names as first names. Moreover, in the author addresses footnote of the PDF version of the original article, the first names were presented as last names and the last names reduced to first initials.

The author line should read as follows: Katerina Mensikova, Michaela Kaiserova, Miroslav Vastik, Sandra Kurcova, Petr Kanovsky.

The online version of the original article can be found under doi:10.1007/s00702-014-1297-9.

K. Mensikova $(\bowtie) \cdot$ M. Kaiserova $\cdot$ M. Vastik $\cdot$ S. Kurcova

P. Kanovsky

Department of Neurology, Faculty of Medicine and Dentistry,

Palacky University, University Hospital, Olomouc,

Czech Republic

e-mail: katmen@centrum.cz 